\title{
Impactos socioambientais e educação ambiental: breve debate a partir do exemplo da Ternium Siderúrgica em Santa Cruz - Rio de Janeiro
}

Socio-environmental impacts and environmental education: a brief debate based on the example of Ternium Industry Stell at Santa Cruz - Rio de Janeiro Impacts socio-environnementales et éducation environnementale : un bref débat sur l'exemple de la Ternium Siderurgique à Santa Cruz - Rio de Janeiro Impactos socioambientales y educación ambiental: un breve debate sobre el ejemplo de la Ternium Siderurgique en Santa Cruz - Rio de Janeiro

\section{Thaís Nayara de Sousa Veríssimo e Erich Porto de Moura}

\section{(2) OpenEdition}

\section{Journals}

\section{Edição electrónica}

URL: https://journals.openedition.org/espacoeconomia/21275

DOI: 10.4000/espacoeconomia.21275

ISSN: 2317-7837

\section{Editora}

Núcleo de Pesquisa Espaço \& Economia

Refêrencia eletrónica

Thaís Nayara de Sousa Veríssimo e Erich Porto de Moura, «lmpactos socioambientais e educação ambiental: breve debate a partir do exemplo da Ternium Siderúrgica em Santa Cruz - Rio de Janeiro», Espaço e Economia [Online], 22 | 2021, posto online no dia 14 janeiro 2022, consultado o 12 agosto 2022. URL: http://journals.openedition.org/espacoeconomia/21275; DOI: https://doi.org/10.4000/ espacoeconomia. 21275

Este documento foi criado de forma automática no dia 12 agosto 2022.

Creative Commons - Atribuição-NãoComercial-Compartilhalgual 4.0 Internacional - CC BY-NC-SA 4.0 https://creativecommons.org/licenses/by-nc-sa/4.0/ 


\section{Impactos socioambientais e} educação ambiental: breve debate a partir do exemplo da Ternium Siderúrgica em Santa Cruz - Rio de Janeiro

Socio-environmental impacts and environmental education: a brief debate based on the example of Ternium Industry Stell at Santa Cruz - Rio de Janeiro Impacts socio-environnementales et éducation environnementale : un bref débat sur l'exemple de la Ternium Siderurgique à Santa Cruz - Rio de Janeiro Impactos socioambientales y educación ambiental: un breve debate sobre el ejemplo de la Ternium Siderurgique en Santa Cruz - Rio de Janeiro

Thaís Nayara de Sousa Veríssimo e Erich Porto de Moura

\section{Introdução}

1 Ao pensar o contexto histórico em que o ambiente passou por grandes conflitos, remetemo-nos à Revolução Industrial, pois esta contribuiu para a consolidação do capitalismo como modo de produção dominante. Segundo Carlos Benedito Martins (apud COSTA, 2016, s/p.), essa revolução não significa apenas a inserção das máquinas a vapor e seus aperfeiçoamentos ao longo das décadas e sim "o triunfo da indústria capitalista", indústria essa que aos poucos reuniu os meios de trabalho - máquinas, terra e ferramentas - nas mãos burguesas, desapropriando o trabalho das grandes massas humanas.

2 Após este fato marcante da história que se propaga, de certa forma até os dias de hoje, evidenciaremos uma relação com o tema proposto neste trabalho, em que uma empresa localizada na zona oeste do Rio de Janeiro, mais especificadamente em Santa Cruz, a 
TKCSA, há muito tempo vem mudando a interação da sociedade com o ambiente do local. Com uma breve história sobre a empresa, iniciaremos por meio de estudos e artigos que corroboram com a temática proposta. Dedicamos este estudo ao que chamam, popularmente, de "chuva de prata", poeira advinda da manipulação do minério de ferro e que, por muitas vezes, é prejudicial à saúde da população de Santa Cruz - Rio de Janeiro (RJ).

3 Ao final deste artigo, embasado em diversos autores, propomo-nos refletir como o "espírito capitalista" vem degradando não apenas os espaços sociais, culturais de certos povos e populações, mas como todo o ambiente, que consequentemente nos afeta, às vezes de forma direta ou indireta. Nessa perspectiva, ressaltaremos como o Estado tem dado garantias para as relações de produção capitalista, atendendo às suas demandas, flexibilizando leis, e concebendo nessa ação o conceito de acumulação por espoliação.

Destacaremos o conceito de Educação Ambiental, que nos traz a consciência de que o ambiente tem seus limites de produção, que não comportam o modelo de produção $\mathrm{e}$ consumo exacerbado, além de propostas socioeconômicas que interagem de maneira mais eficiente e satisfatória com a natureza. E desta maneira refletiremos acerca de propostas mais sustentáveis que favoreçam a economia e o ambiente, superando a dinâmica econômica capitalista e seu impacto às populações e territórios.

5 Esta pesquisa é baseada no trabalho de conclusão de curso submetido ao corpo docente do curso de Pós-graduação em Educação Ambiental das Faculdades Integradas CampoGrandenses (FIC), mantidas pela Fundação Educacional Unificada Campograndense (FEUC), como parte dos requisitos necessários à obtenção do grau de Especialista em Educação Ambiental.

\section{Ternium (TKCSA) e a "chuva de prata"}

6 A Ternium Brasil, anteriormente chamada ThyssenKrupp Companhia Siderúrgica do Atlântico, é uma das maiores siderúrgicas da América Latina, tendo $9 \mathrm{~km}^{2}$, onde hoje há uma "reserva de 160 hectares de mangue" e "foram desmatados 23 hectares" (PINTO, 2016). A siderúrgica foi construída no Bairro Residencial João XXIII e com uma importante área ecológica, localizado no bairro de Santa Cruz - Rio de Janeiro, às margens da Baía de Sepetiba. Segundo Janaína Pinto (2016) o local é tido como Distrito Industrial de Santa Cruz, sendo as fábricas aceitas pelo Estado e tendo "benefícios fiscais dos governos estadual e municipal". Além de residencial, este conjunto é um bairro que mantem raízes rurais que é proporcionada pela baía de Sepetiba. "Tradicionalmente, a natureza fértil da baía garantiu e ainda garante - embora de maneira cada vez mais precária - a vida de boa parte dos/as moradores/as dali" (PINTO, 2016).

Desde $2010^{1}$, a então Companhia Siderúrgica do Atlântico (TKCSA) funciona com uma de suas unidades em Santa Cruz. Há anos os moradores desse bairro convivem com a produção de pó e de fumaça química que é lançada no ar, na água e na terra e com as consequências da atividade poluente da siderúrgica. 0 surgimento da empresa no local gerou empregos, cujo número parece não justificar os impactos, violações de direitos e flexibilização da lei. Mas os moradores e pescadores respondem esta pergunta com a luta e a exigência de justiça para pagar a conta dos prejuízos realizados pela empresa.

Desde o início da drenagem para a construção da TKCSA a transformação do ambiente e sua deterioração tornaram-se visíveis. A empresa transformou canais que deságuam na Baía de Sepetiba em efluentes oriundos do processo de drenagem, acelerando também a 
degradação da bacia hidrográfica, que compõem uma biota singular e mantém todo o equilíbrio ecológico da baía (PACS, 2012, p. 39).

9 A Baía de Sepetiba abrange, além de parte da Zona Oeste do município do Rio de Janeiro, os municípios de Itaguaí e Mangaratiba. É uma região muito diversificada do ponto de vista ambiental e socioeconômico. Essa área também, nos últimos anos, vem recebendo especial atenção por parte dos grandes projetos portuários e siderúrgicos, devido às suas vantagens logísticas e em termos de custos de operação (PACS, 2012, p. 22). Do ponto de vista ambiental, em seu entorno existem importantes ecossistemas ainda preservados de florestas, restingas - como a da Marambaia - e manguezais. Podem ser encontradas áreas remanescentes da Mata Atlântica, principalmente na Serra do Mar, considerada atualmente uma das 25 áreas mais importantes para a conservação da biodiversidade em todo o mundo. A baía desempenha também um importante papel no abrigo de espécies de aves nativas, endêmicas e ameaçadas de extinção e no refúgio de aves costeiras; serve também como área de descanso para bandos de aves que procuram abrigo em sua vegetação (PACS, 2012, p. 24).

Devido às obras de instalação da siderúrgica na Baía de Sepetiba ocorreram impactos sobre a pesca local. As atividades de drenagem desenvolvidas pela empresa aumentaram a circulação de grandes navios na baía, além de contaminar as águas por meio de metais como cadmio, chumbo e zinco. Esses produtos químicos vazaram em grande volume da falida Ingá Mercantil nos últimos 20 anos, e, a cada drenagem feita pela TKCSA, esses metais pesados que antes estavam assentados no assoalho oceânico, passaram a ser revolvidos retornando para a água e contaminando toda a vida marinha.

Diante de tantas problemáticas ocasionadas pela siderúrgica, a "chuva de prata" ganha destaque. Essa chuva é oriunda de resíduos metálicos - compostos por carbono, ferro, zinco, alumínio e metais pesados como chumbo, cádmio e titânio (KATO, 2013 apud PENA et al., 2016) - que cobriu as casas e causa danos na pele e no aparelho respiratório dos moradores do entorno da empresa, especialmente os de Santa Cruz.

o principal crime denunciado foi o derramamento de ferro-gusa em poços ao ar livre. 0 ferro-gusa é resultado do derretimento do minério de ferro, quando entra em contato com o solo, depois de superaquecido pelo alto-forno, provoca a emissão de toneladas de material particulado - o que significa uma poeira espessa no ar que tomou casas e ruas próximas à João XXII de maneira muito acentuada mais de uma vez". (PINTO, 2016)

12 Esse fenômeno foi alvo de diversas denúncias e permanece ocorrendo, mesmo com todo o envolvimento de parlamentares, do Ministério Público, da Fiocruz, nas denúncias sobre a empresa e seu funcionamento ambientalmente desastroso ${ }^{2}$.

Em setembro de 2016, a TKCSA obteve junto ao Instituto Estadual do Ambiente (INEA) a sua licença de operação depois de funcionar precariamente durante seis anos a partir de um Termo de Ajustamento de Conduta (TAC). Para os moradores da região da Avenida João XXIII, no bairro de Santa Cruz, vizinho ao empreendimento, a licença de operação não alterou a realidade. 0 relato recente de uma moradora revela que a convivência com o pó continua: "Semana passada caiu um bocado. É mais fino do que antes, mas ainda cai”. Outra moradora tampouco confia na água de beber dos bichos. "Troco três vezes por dia. Quando esqueço e vou ver, está cheia de pozinho prateado". Continuam também os relatos sobre a manifestação de doenças dermatológicas, oftalmológicas e respiratórias". (QUINTELA e STRAUTMAN, 2017, s/ p.)

13 A siderúrgica, conhecida por elevar em $76 \%$ as emissões de $\mathrm{CO}^{2}$ na cidade do Rio de Janeiro e por causar o fenômeno da "chuva de prata" em seu entorno, já foi embargada 
pelo Ministério do Trabalho, multada por órgãos ambientais após pressão da sociedade, denunciada em reportagens na grande imprensa e alvo de processos criminais movidos pelo Ministério Público do Estado do Rio de Janeiro (MPRJ) (PACS, 2013). Segundo a jornalista Kelly Lima (LIMA, 2011), tinha sido processada pelo Ministério Público em junho de 2011 pela emissão da "chuva de prata" advinda do auto forno 1 e em dezembro do mesmo ano foram processadas pelo auto forno 2 .

Depois de a CSA entrar em operação, no ano de 2010, um diretor e um gerente foram denunciados pelo Ministério Público do Estado do Rio de Janeiro (MPRJ) por crimes ambientais. $O$ motivo da acusação foi a geração de poluição atmosférica em níveis que poderiam gerar danos à saúde das pessoas, afetando principalmente a comunidade vizinha. Na Ação Penal, eles foram acusados pela prática de quatro crimes ambientais, mas o principal trata do derramamento de ferro-gusa em poços ao ar livre, sem qualquer controle de emissões (SAAVEDRA DURÃO, 2010 apud PENA et al., 2016, p. 56).

Após o início das operações da Companhia Siderúrgica do Atlântico, (TKCSA) não houve a garantia de condições operacionais adequadas, o que desencadeou uma série de eventos de poluição atmosférica, descritos pela população como uma chuva de poeira prateada. Segundo relato de pessoas que moram próximas à instalação da empresa, essa poeira desencadeou problemas respiratórios e dermatológicos que afetam principalmente os idosos e crianças. A poluição aguda, ou chuva de prata como chamam os moradores, é ocasionada pelo armazenamento contínuo do ferro gusa em poços ao ar livre, os poços de basculamento, sem qualquer controle de efluentes gasosos por parte da empresa (PACS, 2012, p. 42).

15 A Fundação Oswaldo Cruz (Fiocruz), entretanto, não tem dúvidas da correlação direta entre a chamada "chuva de prata" - episódios de emissões de partículas - e impactos agudos na saúde de moradores, especialmente problemas respiratórios, dermatológicos e oftalmológicos. A afirmação consta de relatório assinado por cinco especialistas e enviado ao Ministério Público do estado do Rio de Janeiro (MPRJ). No documento, a entidade lamenta ainda o fato de a unidade de vigilância em saúde do trabalhador não ter sido implementada pela CSA (ALENCAR, 2012, s/p.).

O fenômeno da "chuva de prata" se inicia no mesmo ano que a empresa começa suas atividades:

Em dezembro de 2010, o Ministério Público do Estado do Rio de Janeiro denunciou a Thyssenkrupp CSA [...] por quatro crimes ambientais. A ação foi ajuizada pelo Grupo de Atuação Especial de Combate ao Crime Organizado (GAECO) e procurou dar evidências de que a TKCSA - desde a inauguração, em junho daquele ano - gerava poluição atmosférica em níveis capazes de provocar danos à saúde humana". (PINTO apud PACS, 2016)

17 Só no primeiro ano de funcionamento da siderúrgica houve duas chuvas de prata intensas, o que resultou em duas multas para a empresa. Contudo, a chuva de resíduo prateado ocorreu outras vezes, ocasionando multas. Juntamente com as multas o Termo de Ajuste de Conduta (TAC) diagnosticou o fator que gerou a "chuva de prata" que foi o uso "do poço de emergência", e estabeleceu medidas que pudessem solucionar, porém tais medidas não foram cumpridas, já que houve reincidência dos casos (PENA et al., 2016). Todavia, a siderúrgica insiste em afirmar que o pó de grafite que é vazado ao ar não causa nenhum dano à saúde ou ao meio ambiente (PINTO, 2016). 
Recentemente, especificamente em 2017, a TKCSA foi vendida para a Ternium Brasil. E surgiu uma grande questão a ser discutida: quem iria se responsabilizar pelos danos realizados pela TKCSA? Em seu artigo Quintela e $\operatorname{Strautman}^{3}(2017, \mathrm{~s} / \mathrm{p}$.) dizem que:

Moradores e moradoras esperam até hoje por ações que cobram reparações por rachaduras nas casas próximas à linha do trem, interrupção da pesca artesanal, enchente no canal do São Fernando e agravamento dos problemas de saúde provocados pela Chuva de Prata. Segundo a Defensoria Pública, que representa os moradores atingidos nas ações, a falta de uma perícia técnica isenta que busque estabelecer o nexo causal entre o crescente adoecimento e a poluição causada pela siderúrgica ou que permite mensurar os danos causados pelas enchentes ocasionadas pela instalação do empreendimento é o principal impedimento para o andamento dos processos. (QUINTELA e STRAUTMAN, 2017, s/p.)

Infelizmente os moradores da região ainda continuam sem resposta e com a venda da empresa se torna mais um agravo para esta comunidade. E o histórico da atual dona do local que residia a TKCSA, a Ternium Brasil, também não é muito agradável. Esta empresa é de uma família argentina e que acumula problemas socioambientais.

É uma das principais produtoras de aço da América Latina, atuando no México, Argentina, Colômbia e Guatemala. Nesses países acumula uma série de conflitos socioambientais. Em 2013, líderes da comunidade indígena de San Miguel de Aquila interromperam a produção de uma mina de ferro da Ternium, no estado de Michoacán no México, acusando a empresa de não respeitar o pagamento de royalties da mineração para a comunidade. Em função dos protestos, quarenta e cinco pessoas foram presas pelo exército. Em 2012, a Ternium Internacional Guatemala demitiu 27 trabalhadores que formaram um sindicato em uma siderúrgica. (QUINTELA e STRAUTMAN, 2017, s/p.)

Isso mostra que a nova empresa pode continuar com as mazelas a população de Santa Cruz, Rio de Janeiro. Em $2018^{4}$, os moradores da região aproveitaram o ano eleitoral para redigirem uma "carta compromisso sobre impactos da siderurgia", onde apela para os novos governantes do estado do Rio de Janeiro para que possam dar atenção à luta deles. Nesta carta são detalhadas as denúncias e as ações que existem contra a antiga companhia que residia no local.

Entre as denúncias da carta estão as 238 ações contra a companhia e lista de violações, como intimidações das lideranças, pesquisadores e até de comunicadores. Além dos graves episódios de poluição, desrespeito à legislação trabalhista que continuam com a venda da siderúrgica. Além disso, os problemas de saúde e qualidade de vida dos moradores da cidade vem se deteriorando. "As 238 ações colocadas na $1^{\mathrm{a}}$ e na $2^{\mathrm{a}}$ vara de Santa Cruz são sobre os impactos da linha férrea que leva o minério que é da Vale até a Ternium Brasil. E quando o trem passa a gente tem inúmeros casos de paredes rachadas e lajes que estão caindo, então há um impacto direto à saúde, mas também à qualidade de vida e ao cotidiano dessas pessoas e isso vai impactar diretamente nessas vidas como um todo" (BRASIL DE FATO, 2018, s/p.)

21 Vemos que a empresa mudou de dono, mas os problemas que já existiam não foram modificados. A carta, então escrita pelos moradores, pede a suspensão da licença ambiental e da operação da atual empresa, além disso pedem que a saúde pública adeque os tratamentos e prevenções aos casos de doenças proliferadas e relacionadas à siderurgia. Pedem ainda a "revisão das zonas de exclusão de pesca, suspensão e a devolução imediata de todos os incentivos fiscais concedidos à empresa no estado do Rio de Janeiro" e interromper a autorização de água para a Ternium Brasil (BRASIL DE FATO, 2018, s/p.). 

local, são correlacionadas às atividades da TKCSA, que dentro deste processo de acumulação de capital, desvincula ou desapropria a terra dos moradores da região. Em vista disso, nota-se que o modo de produção capitalista se reinventou, restabelecendo novas formas, uma vez que tem utilizado a natureza, desvalorizando-a num primeiro momento, para que os grupos sociais que ali se estabeleciam, e tinham um modo de viver próprio e distinto do preconizado pelo capitalismo, perdessem seu espaço, não sendo mais possível que tais grupos utilizem os recursos naturais para garantia da subsistência.

\section{Educação Ambiental: conscientização crítica da relação sociedade- natureza}

Milton Santos ensina que os espaços "requalificados atendem sobretudo a interesses dos atores hegemónicos da economia e da sociedade, e assim são incorporados plenamente às correntes de globalização" (SANTOS, 1994, pp. 24-25). Por esse ângulo, a globalização econômica tem fornecido uma superioridade sem precedentes aos agentes econômicos - principalmente as indústrias e empresas - que não se sentem devedores de lealdade ou de responsabilidade para com nenhum país, populações tradicionais, região ou localidade do sistema mundial. Torna-se notório que os benefícios que o modelo de desenvolvimento capitalista pode gerar ao transferir sua produção aos países periféricos ficam confinados a uma pequena minoria, enquanto os seus custos e malefícios se distribuem por uma maioria crescente. De acordo com Boaventura de Sousa Santos (1999, p. 297), os países do Norte "especializaram-se" na poluição industrial e em tempos mais recentes tem conseguido exportar parte dessa poluição para os países do Sul, quer sob a forma de venda de lixo tóxico, quer por transferência de algumas indústrias mais poluentes por ser aí menor a consciência ecológica e serem menos eficazes os controles antipoluição.

Parreira e Alimonda (2005, pp. 31-32) explicam que na visão burguesa a natureza começou a ser vista de maneira racionalizada, ou seja, sendo utilizada de maneira benéfica aos interesses capitalistas. 0 processo de desenvolvimento econômico em um ritmo acelerado, concebeu sérios prejuízos ao ambiente que atualmente estão evidenciados, provocando alterações ambientais que afligem e despertam sobre o futuro da humanidade. Por sua vez, Boron et. al. (2007) aborda um fator fundamental para o agravamento da crise ecológica do capitalismo:

A substituição de ciclos e regimes de tempo-espaço naturais por ciclos e regime de tempo-espaço industriais na agricultura tem um impacto prejudicial sobre o meio ambiente, o natural bem como o construído, e sobre o sistema social. Este é um fator fundamental para o agravamento da crise ecológica do capitalismo e para os movimentos contrários a ele. (BORON et al., 2007, p. 369) 
processo de acumulação capitalista tende a não respeitar os ciclos e limites da natureza, sendo prejudicial ao ambiente. O mercado capitalista possui um cálculo imediatista de perdas e lucros e é profundamente contraditório com uma racionalidade ecológica que leve em consideração a temporalidade dos ciclos naturais e as necessidades reais da população.

Dentro desse processo de globalização, há o predomínio do capitalismo liberalizado e da desigualdade ambiental. Nesse sentido,

o conceito de desigualdade ambiental permite apontar o fato de que, com a sua racionalidade específica, o capitalismo liberalizado faz com que os danos decorrentes de práticas poluentes recaiam predominantemente sobre grupos sociais vulneráveis, configurando uma distribuição desigual dos benefícios e malefícios do desenvolvimento econômico. Basicamente, os benefícios destinam-se aos grandes interesses econômicos e os danos a grupos sociais despossuídos.

(ACSELRAD et al., 2012, p. 165) responsabilidade pelos danos gerados ao ambiente, uma vez que, tais malefícios não reincidem com igualdade sobre todos os grupos sociais, alguns locais são considerados ideais para a instalação de indústrias poluidoras, visto que, nessas regiões há uma desregulação econômica e um afrouxamento das leis legitimado pelo Estado. Ou seja, o governo toma decisões que facilitam a instalação de indústrias que não tem comprometimento com a preservação do ambiente do local, e isso ocorre predominantemente em países do Sul, que tem a maioria da população sendo pobre, tal pensamento é sustentado por uma cultura corroborada no Memorando Summers que:

[...] confirmam a lógica explicitada pelo Memorando Summers, redigido em 1991, pelo então economista-chefe do Banco Mundial, e vazado para a imprensa às vésperas da Conferência Rio 92. O documento justificava explicitamente a necessidade de transferir indústrias poluentes para os países menos desenvolvidos, alegando duas razões i) os mais pobres não vivem o tempo suficiente para sofrer os danos ambientais; ii) as mortes nos países pobres têm custos menores que nos países ricos (ACSELRAD et al., 2012, p. 166-167).

Percebe-se que as práticas poluentes estão localizadas, não por acaso, em territórios onde o Estado está determinado a flexibilizar suas leis, através de uma política conservadora de ajustes econômicos, sem maiores preocupações ambientais ou tratando a natureza como um empecilho para o desenvolvimento econômico, tolerando inclusive retrocessos nas leis ambientais e indo em desacordo com a Declaração Universal dos Direitos Humanos (1948).

Todo esse contexto de subserviência da maioria dos países do Sul é chamado de neodesenvolvimentismo, segundo Henri Acselrad et al. (2012, p.169), que significa a inserção de países periféricos na economia internacional, onde o Estado garante a "rentabilidade de projetos vinculados ao mercado de commodities e exploração de recursos naturais". No Brasil, segundo o mesmo autor, este processo de neodesenvolvimentismo se iniciou nos anos 1990, de maneira que o Brasil não diferentemente dos demais países periféricos, também participa deste processo de facilitação de indústrias para que possam, então, se inserir na economia internacional globalizada.

Nesse sentido, o bloco de poder hegemônico no Brasil, composto por interesses empresariais relacionados à terra, ao comércio de dinheiro e às commodities numa combinação do capital mercantil com o capital financeiro - exemplifica a capacidade de o capitalismo sofisticar os seus instrumentos de acumulação através 
da apropriação privada, desempenhando o Estado um papel protagonista no direcionamento da concentração dos recursos (BRANDÃo apud ACSELRAD et al., 2012, p. 169)

[...]. Tal dinâmica implica que os grupos econômicos relacionados ao agronegócio, ao setor de mineração, energia e construção pesada integrem os setores estruturantes do poder econômico e político no país, cujos interesses se mostram centrais na conformação do capitalismo brasileiro e na sua relação com o capitalismo mundial a partir dos anos 1990. (ACSELRAD et al., 2012, p 169)

revela uma gama de processos para que a acumulação possa ocorrer. Dentre elas destaca-se "a privatização de terras e a expulsão violenta de populações camponesas; a conversão de várias formas de direitos de propriedade (comum, coletiva, do Estado etc.) em direitos exclusivos de propriedade privada", recuperando a concepção de acumulação primitiva. Tal concepção demonstra como o capital, em seu contexto geral, expropria e cria maneiras diversas para que possa produzir sem interrupção. Segundo Josafá Carlos de Siqueira (apud RUA, 2007, p. 131), a relação homem-natureza é agravada pela priorização dos valores econômicos e produtivos, em detrimento dos valores humanísticos e éticos. Se considerarmos a natureza um recurso infinito e exclusivo, à disposição da lógica do mercado, concebemos a mesma uma fragmentação e separação da sociedade, ignorando a complexidade que envolve o meio ambiente.

A natureza é explorada por nossa sociedade como se fosse um recurso inesgotável, vista de forma fragmentada, sem a preocupação e o respeito com as relações dinâmicas do equilíbrio ecológico e sua capacidade de suportar os impactos sobre ela, o que resulta nos graves problemas ambientais da atualidade. A natureza percebida a partir de uma visão mais complexa, em sua totalidade, potencializaria a construção de uma relação entre os seres humanos em sociedade e a natureza de forma mais integrada, cooperativa e, portanto, sustentável socioambientalmente. É aqui que a educação ambiental vem sendo chamada para "resolver" os problemas da nossa sociedade urbano-industrial. Mas qual é mesmo a "natureza" desses problemas? (GUIMARÃES, 2007, p. 87)

Desta forma, uma das maneiras de compreender como o sistema econômico capitalista afeta o ambiente, e, consequentemente, a vida e reprodução das pessoas, é através da Educação Ambiental. Segundo Rachel Trajber (2007, p. 144) "o desafio proposto para a educação ambiental é compor uma concepção crítica que aponte para a descoberta conjunta de qualidade de vida para as pessoas e, ao mesmo tempo, de cuidar do nosso pequeno planeta". Ou seja, a Educação Ambiental não é uma concepção simplória da natureza, pelo contrário, está disposta a intervir na crise ambiental de valores, propondo sociedades mais sustentáveis e articuladas politicamente.

Trata-se de efetivar mudanças políticas e estruturais na forma de organização da produção, distribuição e consumo bem como nas relações sociais decorrentes desse modo de produção. No momento em que reconhecemos a existência de um sistema 
de valores mais amplo, distante das motivações individualistas e competitivas inspiradas pelo desejo provocado por agentes como o marketing e a publicidade, podemos exercer outra dimensão profundamente humana: a da responsabilidade.

(TRAJBER, 2007, p. 144)

34 Cada vez mais o homem tem se desconectado da natureza, percebendo a mesma exclusivamente como algo necessário para a manutenção de nossas necessidades individuais, precisamos resgatar meios tradicionais de lidar com o ambiente, havendo desse modo uma conexão mais coletiva e crítica com a natureza, onde possamos encontrar na mesma, significados reais e próximos à vida prática. Nessa perspectiva, a Educação Ambiental nos convida a construir uma sociedade mais integrada nas relações com o ambiente.

Como a educação ambiental pode nos ajudar a construir uma sociedade mais integrada em nossas relações com as pessoas e também com o meio ambiente? Para garantir qualidade de vida para a nossa e para as futuras gerações, precisamos mudar valores e atitudes individuais e coletivas, a começar por viver com o planeta em mente. Acreditamos que um pensamento crítico mais responsável e solidário, por ser comprometido com o coletivo, e voltado para a simplicidade, por ser menos individualista, consumista e competitivo, pode nos levar, e aos nossos jovens estudantes, a uma postura que permita um presente e um futuro sustentáveis. (TRAJBER, 2007, p. 144)

A Educação Ambiental nos oferece novas alternativas, para mudanças no modelo socioeconômico atual, onde o consumo exacerbado não seja o foco e que a proteção, o reflorestamento, a preservação ambiental seja a questão principal. Desse modo, precisamos ampliar os movimentos unificados, onde o objetivo principal é a justiça ambiental e o direito de decidir democraticamente as prioridades pertencentes às populações tradicionais, e, que tais movimentos não se estabeleçam apenas nas ruas, mas também nas instituições universitárias e espaços públicos, para que ganhe dimensão e as pessoas tenham consciências das lutas desses povos que vem sofrendo com os impactos ambientais.

Uma reorganização do conjunto do modo de produção e de consumo é necessária, baseada em critérios exteriores ao mercado capitalista: as necessidades reais da população e a defesa do equilíbrio ecológico. Isto significa uma economia de transição ao socialismo, na qual a própria população - e não as "leis do mercado" ou um Bureau político autoritário - decide, democraticamente, as prioridades e os investimentos. Esta transição conduziria não só a um novo modo de produção e a uma sociedade mais igualitária, mais solidária e mais democrática, mas também a um modo de vida alternativo, uma nova civilização, ecossocialista, para além do reino do dinheiro, dos hábitos de consumo artificialmente induzidos pela publicidade, e da produção ao infinito de mercadorias inúteis. (QUERIDO, 2010, p. 182)

\section{Conclusão}

Desde o seu nascedouro, o capitalismo se nutre de conflitos e segregação social. A desapropriação do meio de trabalho, juntamente com a restrição da propriedade, dá origem a diferentes conflitos sociais. A acumulação de capital é a base deste modelo socioeconômico, o que afeta todo meio de vida, já que é necessário não apenas mão-deobra, mas também matéria-prima para a produção de mercadoria em larga escala. Nesta lógica mercantil, emergem desvantagens tanto aos trabalhadores como ao 
ambiente, que é extremamente explorado com a finalidade de larga produção e obtenção de capital a partir da mais-valia.

Embasados neste contexto capitalista, como se pode observar no decorrer deste artigo, as políticas dos países subdesenvolvidos, localizados no Sul do Globo Terrestre, são de facilitação e regulamentação de um capitalismo desenfreado, trazendo graves consequências para o ambiente e a população do local. Evidencia-se que grandes empresas, indústrias, multinacionais, com a contribuição do Estado, tendem a se instalar em países que dão "liberdades" para suas produções, acarretando sérios problemas para populações como: povos indígenas, pescadores artesanais, ribeirinhos, entre outros, que são expulsos de suas terras para que megaprojetos se estabeleçam com a pretensa ideia de trazer "progresso" e "desenvolvimento".

Constatamos que as decisões ambientais geralmente representam acordos feitos pela minoria da sociedade que detêm o poder econômico e político, enquanto os grupos afetados pela lógica capitalista convivem com toda a poluição e desastres ecológicos desencadeados pela ação das grandes empresas, tornando desigual a distribuição de ganhos e perdas dentro da sociedade.

Sendo assim, precisamos pensar em alternativas que vão além do próprio modelo vigente e de suas regras de acumulação, baseadas na satisfação das verdadeiras necessidades sociais e do equilíbrio ecológico, que são diferentes das pretensas necessidades produzidas artificialmente pela publicidade e pelo mercado capitalista. Nessa perspectiva, há estudos sobre ecossocialismo, economia ecológica e Educação ambiental, onde se busca uma conexão mais crítica e coletiva com a natureza, alcançando qualidade de vida para a sociedade bem como cuidado com o planeta e seus recursos naturais.

Da mesma maneira, é necessário que tenhamos urgentemente uma vigilância de fiscalização eficiente, evitando possíveis negligências e crimes ambientais cometidos pelas grandes indústrias. $O$ governo tem importante papel de atender às necessidades da população, de modo que não exproprie as pessoas de seus locais, de suas moradias e de suas amizades. Carecemos de reconsiderar o consumo, o tipo de produção e colocar a vida em primeiro lugar ao invés do lucro e do consumo exacerbado.

\section{BIBLIOGRAFIA}

ACSELRAD, Henri et al. Desigualdade Ambiental e Acumulação por Espoliação: O que está em Jogo na Questão Ambiental? E-Cadernos CES, n. 17, 2012, p. 164-183. Disponível em: < https:// www.ces.uc.pt/e-cadernos/media/ ecadernos17/07.ColetivoBras.Pesq.DesigualdadeAmbiental.pdf>. Acesso em: 10 de maio de 2019.

ALENCAR, Emanuel. Funcionando sem licença definitiva há quatro anos, CSA tem prazo para regularização estendido. Jornal O Globo, Out/2014. Disponível em: < https://oglobo.globo.com/ rio/funcionando-sem-licenca-definitiva-ha-quatro-anos-csa-tem-prazo-para-regularizacaoestendido-14331049\#ixzz4wc9NMBbg >. Acesso em 15 de outubro de 2017. 
BORON, Atilio A.; AMADEO, Javier; GONZÁLEZ, Sabrina. A teoria marxista hoje: Problemas e perspectivas. Buenos Aires: CLACSO, 2007. Disponível em: < http://biblioteca.clacso.edu.ar/ clacso/formacion-virtual/20100715073000/boron.pdf >. Acesso em: 15 de setembro de 2017.

Brasil de Fato. Moradores de Santa Cruz (RJ) produzem carta compromisso sobre impactos da siderurgia. Rio de Janeiro: Brasil de Fato, 19 de set. de 2018. Disponível em: < https:// www.brasildefato.com.br/2018/09/19/moradores-de-santa-cruz-produzem-carta-compromissosobre-impactos-da-siderurgia/ >. Acesso em: 05 de dezembro de 2018.

COSTA, André. As influências da Revolução Industrial no surgimento da Sociologia. Linkedin, fev/ 2016. Disponível em: < https://pt.linkedin.com/pulse/influ\%C3\%AAncias-da-

revolu\%C3\%A7\%C3\%A3o-industrial-surgimento-sociologia-andr\%C3\%A9-costa >. Acesso em: $13 \mathrm{de}$ setembro de 2017.

HARVEY, David. O novo Imperialismo. São Paulo: Loyola, $2^{\mathrm{a}}$ ed. 2005.

LIMA, Kelly. CSA é novamente denunciada no RJ por crime ambiental. Estadão, 2011. Disponível em: < https://economia.estadao.com.br/noticias/negocios,csa-e-novamente-denunciada-no-rjpor-crime-ambiental,70717e >. Acesso em: 15 de junho de 2019.

PACS. TKCSA: Companhia Siderúrgica do Atlântico: Impactos e Irregularidades na Zona Oeste do Rio de Janeiro. Rio de Janeiro: PACS e Fundação Rosa Luxemburgo, 3ª ed., fev/2012. Disponível em: < http://www.pacs.org.br/files/2013/01/TKCSA.pdf >. Acesso em: 12 de outubro de 2017.

\#PareTKCSA. Disponível em: < http://paretkcsa.org/ >. Acesso em: 12 de outubro de 2017.

PARREIRA, Clélia; ALIMONDA, Héctor. Políticas Públicas Ambientais Latino-Americanas. Brasília: Flacso-Brasil, Editorial Abaré, 2005.

PENA, Caroline Brasileiro; et al. As Fragilidades do Sistema de Licenciamento Ambiental no Brasil com Base No Estudo de Caso da Companhia Siderúrgica do Atlântico. Revista Científica Interdisciplinar, № 4, volume 3, artigo ํㅡ 4, Outubro/Dezembro 2016, pág. 45 - 62, PDF.

PINTO, Janaína Bezerra. O papel da Responsabilidade Social Empresarial em cenários de conflitos ambientais siderúrgicos - O caso da TKCSA na periferia carioca de Santa Cruz. Porto Alegre: IV Congresso Brasileiro de Estudos Organizacionais, 2016, PDF.

QUERIDO, Fabio Mascaro. As utopias indisciplinadas de um marxismo para o século XXI: o marxismo como crítica da modernidade Entrevista com Michael Löwy. 2010. PDF.

QUINTELA, Sandra; STRAUTMAN, Gabriel. A Ternium vai pagar a dívida financeira e social da CSA?. [S.1], PACS, 25 de ago. de 2017. Disponível em: < http://www.br.org.br/2017/08/25/aternium-vai-pagar-a-divida-financeira-e-social-da-csa/ >. Acesso em: 04 de dezembro de 2018. RUA, João. Paisagem Espaço e Sustentabilidade: Uma Perspectiva Multidimensional da Geografia. Rio de Janeiro: PUCRJ, 2007, PDF.

SANTOS, Boaventura de Sousa. Pela mão de Alice: O social e o político na pós modernidade. Portugal: Edições Afrontamento, $7^{a}$ ed., jun/1999. PDF.

SANTOS, Milton. Técnica, Espaço, Tempo: Globalização e Meio Técnico-Científico Informacional. São Paulo: Hucitec, $1^{\mathfrak{a}}$ ed., 1994.

TKCSA, meio ambiente e política de estado. Na Transversal do Tempo, ago/2014. Disponível em: < https://natransversaldotempo.wordpress.com/2014/08/06/tkcsa-meio-ambiente-e-politica-deestado-tkcsa-tkcsanao/ >. Acesso em: 13 de outubro de 2017. 
TRAJBER, R. Cidadania e consumo sustentável: nossas escolhas em ações conjuntas. In: MELLO, S.S.; TRAJBER, R. (Coord.). Vamos cuidar do Brasil: conceitos e práticas em Educação Ambientalna escola. Brasília: UNESCO, p. 143-150, 2007.

\section{NOTAS}

1. \#PARETKCSA, campanha criada com o intuito de retirar a empresa do local e denunciar os "estragos" ambientais e na saúde da população local.

2. Revista online Na Transversal do Tempo, 2014.

3. QUINTELA, Sandra; STRAUTMAN, Gabriel. A Ternium vai pagar a dívida financeira e social da CSA?. Rio de Janeiro: Instituto PACS, 25 de agosto de 2017.

4. BRASIL DE FATO. Moradores de Santa Cruz (RJ) produzem carta compromisso sobre impactos da siderurgia. Rio de Janeiro: BRASIL DE FATO, 19 de setembro de 2018.

\section{RESUMOS}

O objetivo desse texto é o de realizar uma reflexão sobre educação ambiental a partir dos estudos sobre a Ternium Siderúrgica (antiga TKCSA - ThyssenKrupp Companhia Siderúrgica do Atlântico), especialmente sobre a conhecida "chuva de prata" ocasionada por descuidos da empresa e os problemas relacionados a este fenômeno. Para isso faço uso de artigos, de matérias em jornais e revistas, livros e relatos feitos pelo movimento \#PARETKCSA, nascido com a finalidade de lutar contra as injustiças socioambientais realizadas pela empresa CSA localizada na zona oeste do Rio de Janeiro, no bairro Santa Cruz, na Baía de Sepetiba e em todo o entorno.

This paper presents a short report on socio-environmental education and environmental education, notably the called "silver rain". Taking as a case study the Ternium Steel Industry at Rio de Janeiro, we are based on newspapers, magazines, and books, as well as on the movement called \#PARETKCSA [\# STOPTKCSA]formed for fighting against the socio-environmental injustices, whose impacts affects the neighborhood of Santa Cruz and the whole environ of the Sepetiba Bay as well.

Cet article est une petite présentation sur l'éducation socio-environnementale et éducation environnementale, notamment le cas de la pluie acide [chuva de prata] provoquée par la Sidérurgique Ternium située à Rio de Janeiro. Notre recherche est basée sur des materiaux de presse, des revues et des livres, mais aussi du mouvement \#PARETKCSA [\# ARRÊTEZTKCSA] crée de façon à lutter contre les injustices socio-environnementales, dont les effets ont atteint si le quartier de Santa Cruz que les alentours de la Baie de Sepetiba à Rio.

Este artículo es una pequeña presentación sobre la educación socioambiental y la educación ambiental, en particular el caso de la lluvia ácida [chuva de prata] provocada por la siderúrgica Ternium ubicada en Río de Janeiro. Nuestra investigación se basa en materiales de prensa, revistas y libros, pero también en el movimiento \#PARETKCSA [\#DETENERTKCSA] creado para 
luchar contra las injusticias socioambientales, cuyos efectos han llegado tanto al barrio de Santa Cruz como a los alrededores de Bahía de Sepetiba en Río.

\section{ÍNDICE}

Palavras-chave: Ternium Siderúrgica, chuva de prata, educação ambiental, impactos socioambientais, Baía de Sepetiba-RJ.

Mots-clés: Ternium Sidérugique ; pluie acide ; éducation environnementale ; impacts socioenvironnementales ; Baie de Sepetiba - Rio de Janeiro

Keywords: Ternium Steel Industry; silver rain, environmental education, socio-environmental impacts, Sepetiba Bay - Rio de Janeiro.

Palabras claves: Ternium Siderúrgica; lluvia ácida ; educación ambiental; impactos socioambientales; Bahía de Sepetiba - Río de Janeiro

\section{AUTORES}

\section{THAÍS NAYARA DE SOUSA VERÍSSIMO}

Especialista em Educação Ambiental e graduada em Ciências Sociais pela Fundação Educacional Unificada Campo-grandense (FEUC) e em História pelo Centro Universitário Facvest (Unifacvest). Atualmente é professora da rede pública de ensino do município do Rio de Janeiro-RJ. E-mail: thais_zac@hotmail.com.

\section{ERICH PORTO DE MOURA}

Mestre e graduado em Geografia pela Faculdade de Formação de Professores (FFP) da Universidade do Estado do Rio de Janeiro (UERJ). Atualmente é professor da rede pública de ensino do município de Pinheiral - RJ. E-mail: erichmoura@gmail.com. 